\title{
Erratum to: Does Politics Influence Hiring? Evidence from a Randomized Experiment
}

\author{
Karen Gift ${ }^{1}$ - Thomas Gift ${ }^{2}$
}

Published online: 11 August 2015

(C) Springer Science+Business Media New York 2015

\section{Erratum to: Polit Behav \\ DOI: 10.1007/s11109-014-9286-0}

In the original publication, the authors noted in the text (under the heading "Building Resumes") that they attached "addresses to the resumes, using real streets (but not genuine house numbers) in the chosen counties." In reviewing files after the publication of the article, it came to the authors' attention that certain real addresses were inadvertently used, and that addresses came not just from the chosen counties, but from the greater metropolitan areas of the counties under investigation (e.g., the greater Dallas-Fort Worth and San Francisco metropolitan areas). The authors did not intend for real addresses to be used to protect human subjects, as specified in their IRB protocol. Because employers primarily contact candidates by phone and email, however, the oversight is unlikely to have had negative consequence on human subjects.

Additionally, in Column 8 of Table 2, for the $\mathrm{C}^{\text {Resume }}$ coefficient, the number in the article is: -40.129 . This should read: -0.129 . This error was erroneously introduced during the production process.

The online version of the original article can be found under doi:10.1007/s11109-014-9286-0.

Thomas Gift

thomas.gift@duke.edu

Karen Gift

karen.m.gift@gmail.com

1 School of Law, Duke University, Durham, NC, USA

2 Department of Political Science, Duke University, 140 Science Drive, 208 Gross Hall, Durham, NC 27708, USA 